\title{
Spectrum of Placental Changes in Pregnancy Induced Hypertension
}

\author{
Vandana Porwal*, Deepali Jain, Seema Gupta, Shweta Khandelwal and Neena Kasliwal \\ Dept of Pathology, JLN Medical College, Ajmer, Rajasthan, India
}

\section{ABSTRACT}

Background: PIH also known as toxaemia of pregnancy, is a major cause of maternal and perinatal morbidity and mortality worldwide. The present study was hence undertaken to analyse the effects of PIH on placenta as these changes serve as a guide to the duration and severity of disease.

Methods: A prospective hospital based study was conducted from July 2012 to July 2013 in Department of Pathology, J.L.N. Medical College, Ajmer (Rajasthan). The study was done in 60 placentae, 30 placentae from uncomplicated full term deliveries formed the "Control Group" and 30 placentae from hypertensive pregnancies formed the "Study Group". Sections were taken from placenta and processed for histopathological examination.

Results: The striking villous abnormalities observed in the study group were cytotrophoblastic proliferation (83.34\%), thickening of basement membrane (66.67\%), fibrinoid necrosis (36.67\%), obliterative endarteritis (60\%), decreased villous vascularity (60\%) and paucity of vasculosyntitial membranes.

Conclusion: The gross abnormalities and villous lesions in PIH $(\mathrm{p}<0.001)$ were statistically significant.

Keywords: Placenta, Pregnancy Induced Hypertension (PIH), Villous Abnormalities

\section{Introduction}

Placenta is a unique and wonderful organ said to be the most accurate record of infant's prenatal experience. ${ }^{[1]} \mathrm{A}$ fetus, a placenta and a mother form a composite system of dynamic equilibrium. ${ }^{[2]}$ The placenta performs diversity of functions, ranging from anchoring the fertilized ovum, preventing its rejection by the maternal immune system to enabling the transport of nutrients and wastes between the mother and the embryo/fetus. ${ }^{[3]}$

Hypertensive disorders complicating pregnancy are common and form one of the deadly triads along with haemorrhage and infection, which result in large number of maternal deaths and thereof foetal deaths. ${ }^{[4]}$ Maternal hypertension is diagnosed in $7 \%$ of all deliveries and is associated with $22 \%$ of all perinatal deaths and $30 \%$ of all maternal deaths. ${ }^{[5]}$ These hypertensive disorders causes decreased placental perfusion due to vasospasm of maternal blood vessels. ${ }^{[6]}$

Placenta is said to be the mirror of maternal and fetal status reflecting the changes due to maternal hypertension. So the present study was designed to compare the morphological and histological changes in the placenta of normal and hypertensive mothers.

\section{Material and Methods}

A prospective hospital based study was conducted from July 2012 to July 2013 in Department of Pathology,
J.L.N. Medical College, Ajmer (Rajasthan).The placentae were collected from the Department of Obstetrics and Gynaecology of Rajkiya Mahila Chikitsalaya, Ajmer (Rajasthan).

The study was done in 60 placentae, 30 placentae from uncomplicated full term deliveries formed the "Control Group" and 30 placentae from hypertensive pregnancies formed the "Study Group" having BP ranged 140/90 mm $\mathrm{Hg}$ or above with / without edema and/or proteinuria and convulsions.

Inclusion Criteria: Pregnant women aged between 18-35 years, gestational age between $34-40$ weeks of gestation, singleton pregnancy with presence of live foetus, deliveries by either vaginal route or caesarean section were included.

Exclusion Criteria: Pregnant women who did experience any complication during pregnancy like diabetes mellitus, hypothyroidism, anaemia, cardiac disease, abruption placentae, multiple pregnancies, jaundice and maternal malnutrition were excluded from study. Also women having hypertension before pregnancy were also excluded.

Statistical Analysis: Descriptive statistics were used to analyse the data. They were represented as Mean \pm SD. The statistical difference between the means of control group and study group were analysed by using student unpaired 
" $\mathrm{t}$ " test. A ' $P$-value' of less than 0.05 was considered to be statistically significant.

Method of Sample Collection Placentae with umbilical cord and attached membranes were collected soon after delivery. The umbilical cord was cut at a distance of 5 centimeters from the site of attachment. Placentae were drained completely of blood, washed with water and weighed before formalin fixation on a weighing machine graduated in grams (gm). Placentae diameter was measured with the help of a measuring tape in centimeters $(\mathrm{cm})$. General shape of placentae were ascertained. Then they were examined for gross abnormalities. The gross abnormalities were quantified using semiquantitative methods as "absent" (no visible lesion), "+" (focally distributed lesions), and "++" (extensive lesions). The gross findings were further confirmed by microscopic examination.

All placentae were cut along maximum diameter in two equal halves and then were further cut in small pieces. Two sections each from central and peripheral areas were taken. Additional sections were taken from grossly abnormal lesions. Sections were stained with the hematoxylin and eosin ( $\mathrm{H}$ and $\mathrm{E})$ stain. One hundred villi were counted from each of the four sections obtained and histological changes expressed as percentage. In addition, depending on the need, special stains like periodic acid Schiff (PAS), Von Kossa, and Masson's trichrome (MT) stains were used to highlight the membrane abnormalities and elastic tissue.

\section{Results}

The present study included 60 placentae, 30 placentae each of control and study groups. Gross morphological features and macroscopic lesions in the present study among both groups are compared in Table 1 and Table 2 respectively.

The mean placental weight of hypertensive pregnancies was $409 \pm 88.69 \mathrm{~g}$, the least weight recorded being $200 \mathrm{~g}$ whereas mean placental weight of normal pregnancies was $581 \pm 91.38 \mathrm{~g}$, the heaviest being $700 \mathrm{~g}$ in the present study. (Table-1) $(\mathrm{p}<0.001)$. The mean diameter of the placenta was less in study group $(16.97 \pm 3.34)$ as compared to control group $(19.13 \pm 3.53)$. (Table-1) $(\mathrm{p}<0.05)$

Majority of the placentae were round in both groups. The cord length ranged from 20 to $60 \mathrm{~cm}$. The commonest mode of insertion of the umbilical cord into the placenta was central $(80 \%)$, followed by eccentric $(20 \%)$, and velamentous insertion ( $1 \%$ ) being the least common. Battledore insertion was not observed in the present study. True and false knots were seen occasionally in hypertensive cases.

Placental infarct appears firm, dark red in colour. As it turns older, it becomes hard white mass with granular appearance. Intervillous thrombus resembles infarcts but in fresh tissues they have more of an orange tan colour than the darker colour of acute infarcts. In the present study, the incidence of significant placental infarction $(>5 \%$ surface area involved) was $12(40 \%)$ and intervillous thrombus was $11(36.66 \%)$ in the study group. $(\mathrm{p}<0.01$ and $\mathrm{p}<0.05$, respectively) (Table- 2)

Perivillous fibrin deposition refers to grossly visible plaque like placental lesion observed in $33.33 \%$ of cases in study group. $(\mathrm{p}>0.05)$ (Table-2) Calcification is seen as a blue black area confirmed by Von Kossa stain seen in $66.66 \%$ cases of study group as compared to $46.66 \%$ cases of control group. A single case each of retoplacental hematoma (3.33\%) and placental cyst (3.33\%) was noted in study group. Villous abnormalities seen histopathologically among both groups are compared in Table 3 . The terminal villi of the mature placenta usually contain 2-6 capillaries. The possible deviations from this vasculature are encountered namely villous avascularity, hypovascularity and hypervascularity. Marked villous hypovascularity was seen in $60 \%$ of hypertensive cases. $(\mathrm{p}<0.001)$

Cytotrophoblastic proliferation could be seen beneath the syncytiotrophoblast and external to the basement membrane as lighter stained nuclei, present in a single row (Fig 1) whereas syncytial knots were seen as focal aggregates of syncytial nuclei forming a multinucleated protrusion from the villous surface. Both were found to be significantly higher in hypertensive cases as compared to controls. $(\mathrm{p}<0.001)$

Vasculosyncytial Membrane was seen in the villous as attenuated areas of syncytiotrophoblast, which over lied and appeared to fuse with the wall of the adjacent dilated foetal capillary. Vasculosyncytial membrane in less than $5 \%$ of villi was considered significant and was observed in 27 cases (90\%) while none of the control showed significant vasculosyncytial membrane deficiency. $(p<0.001)$ The basement membrane was seen under high power in PAS stained sections as magenta coloured membrane separating the trophoblastic mantle from the mesenchymal core. An abnormal degree of basement membrane thickening $(>3 \%)$ was observed in $66 \%$ cases of study group. $(\mathrm{p}<0.001)$

Fibrinoid necrosis was seen in HE stained sections as small nodules of homogenous eosinophilic material within the villi. At places the fibrinoid material had enlarged pushing the basement membrane and compressing the entire villous stroma $(p>0.05)$. Villous stromal fibrosis was observed in sections stained with Masson Trichome stain as blue coloured collagen fibers within the core of the villi. Villous stromal fibrosis was seen to be significantly higher in study $\operatorname{group}(\mathrm{p}<0.001)$. 
Obliterative endarteritis of the fetal stem arteries is characterised by swelling and proliferation of intimal cells, together with thickening and reduplication of the basement membrane.In the present study, obliterative endarteritis was observed only in study group. X cell of Wilkin refers to extra villous cytotrophoblastic cells formed due to localized villous ischemia seen in $33.33 \%$ of cases of study group.

Table 1 : Placental morphology in both groups.

\begin{tabular}{|l|c|c|}
\hline Gross Features & Control Group n (\%) & Study Group n (\%) \\
\hline$\leq 500$ & $7(23.33)$ & $28(93.33)$ \\
\hline$>500$ & $23(76.66)$ & $(6.66)$ \\
\hline \multicolumn{3}{|c|}{ Placental Weight* (gm) } \\
\hline$\leq 20 \mathrm{~cm}$ & $19(63.33)$ & $27(90)$ \\
\hline$>20 \mathrm{~cm}$ & $11(36.66)$ & $3(10)$ \\
\hline \multicolumn{2}{|c|}{ Umblical Cord Length } \\
\hline$>35 \mathrm{~cm}$ & $11(36.66)$ & $17(56.66)$ \\
\hline True knots & $19(63.33)$ & $13(43.33)$ \\
\hline False knots & - & $1(3.33)$ \\
\hline
\end{tabular}

$n=$ No. of cases (30); * Placental Weight $<0.001$ HS; * Placental Diameter $<0.05 \mathrm{~S}$

Table 2: Macroscopic placental lesions in both groups.

\begin{tabular}{|c|c|c|}
\hline & Control Group n (\%) & Study Group n (\%) \\
\hline \multicolumn{3}{|c|}{ Infarction } \\
\hline$<5 \%$ & $6(20)$ & - \\
\hline$>5 \%$ & $2(6.6)$ & $12(40)$ \\
\hline \multicolumn{3}{|c|}{ Perivillous fibrin deposits } \\
\hline $0-4 \%$ & $1(3.33)$ & $1(3.33)$ \\
\hline $5-9 \%$ & - & $4(13.33)$ \\
\hline $10-25 \%$ & - & $2(6.66)$ \\
\hline$>25 \%$ & - & $4(13.33)$ \\
\hline \multicolumn{3}{|c|}{ Intervillous thrombus } \\
\hline Absent & $27(90)$ & $19(63.33)$ \\
\hline+ & $1(3.33)$ & $7(23.33)$ \\
\hline++ & $2(6.66)$ & $4(13.33)$ \\
\hline \multicolumn{3}{|c|}{ Calcification } \\
\hline Absent & $16(53.33)$ & $10(33.33)$ \\
\hline+ & $12(40)$ & $16(53.33)$ \\
\hline++ & $2(6.66)$ & $4(13.33)$ \\
\hline Retroplacental hematoma & - & $1(3.33)$ \\
\hline Cyst & - & $1(3.33)$ \\
\hline
\end{tabular}

Table 3: Microscopic placetal villous lesions in both groups.

\begin{tabular}{|c|c|c|}
\hline & Control Group n (\%) & Study Group n (\%) \\
\hline \multicolumn{3}{|c|}{ Villous Vascularity } \\
\hline Normal & $27(90)$ & $10(33.34)$ \\
\hline Increased & $3(10)$ & $2(6.66)$ \\
\hline Decreased & - & $18(60)$ \\
\hline \multicolumn{3}{|c|}{ Cytotrophoblastic proliferation } \\
\hline$\leq 20 \%$ & $30(100)$ & $5(16.66)$ \\
\hline$>20 \%$ & - & $25(83.34)$ \\
\hline \multicolumn{3}{|c|}{ Syncytial knots } \\
\hline$\leq 30 \%$ & $28(93.33)$ & $2(6.67)$ \\
\hline$>30 \%$ & $2(6.67)$ & $28(93.33)$ \\
\hline
\end{tabular}




\begin{tabular}{|l|c|c|}
\hline \multicolumn{2}{|c|}{ Control Group n (\%) } & Study Group n (\%) \\
\hline \multicolumn{2}{|c|}{ Vasculosycytial membrane } & $27(90)$ \\
\hline$\leq 5 \%$ & - & $3(10)$ \\
\hline$>5 \%$ & $30(100)$ & $10(33.33)$ \\
\hline \multicolumn{1}{|c|}{ Basement membrane thickening } \\
\hline$\leq 3 \%$ & $30(100)$ & $20(66.67)$ \\
\hline$>3 \%$ & - & $16(53.33)$ \\
\hline \multicolumn{3}{|c|}{ Fibrinoid necrosis } \\
\hline$\leq 3 \%$ & $18(60)$ & $14(36.67)$ \\
\hline$>3 \%$ & $8(26.66)$ & $8(36.66)$ \\
\hline$\leq 6 \%$ & Villous stromal fibrosis & $19(63.33)$ \\
\hline$>6 \%$ & $25(83.33)$ & $18(60)$ \\
\hline Endarteritis obliterans & - & $13(43.33)$ \\
\hline Intervillous haemorrhage & - & $13(43.33)$ \\
\hline$X$ cells of Wilkin & - & \\
\hline
\end{tabular}

rvillous haemorrhage (H\&E, x100); (c) X cells of Wilkin (H\&E, x200)

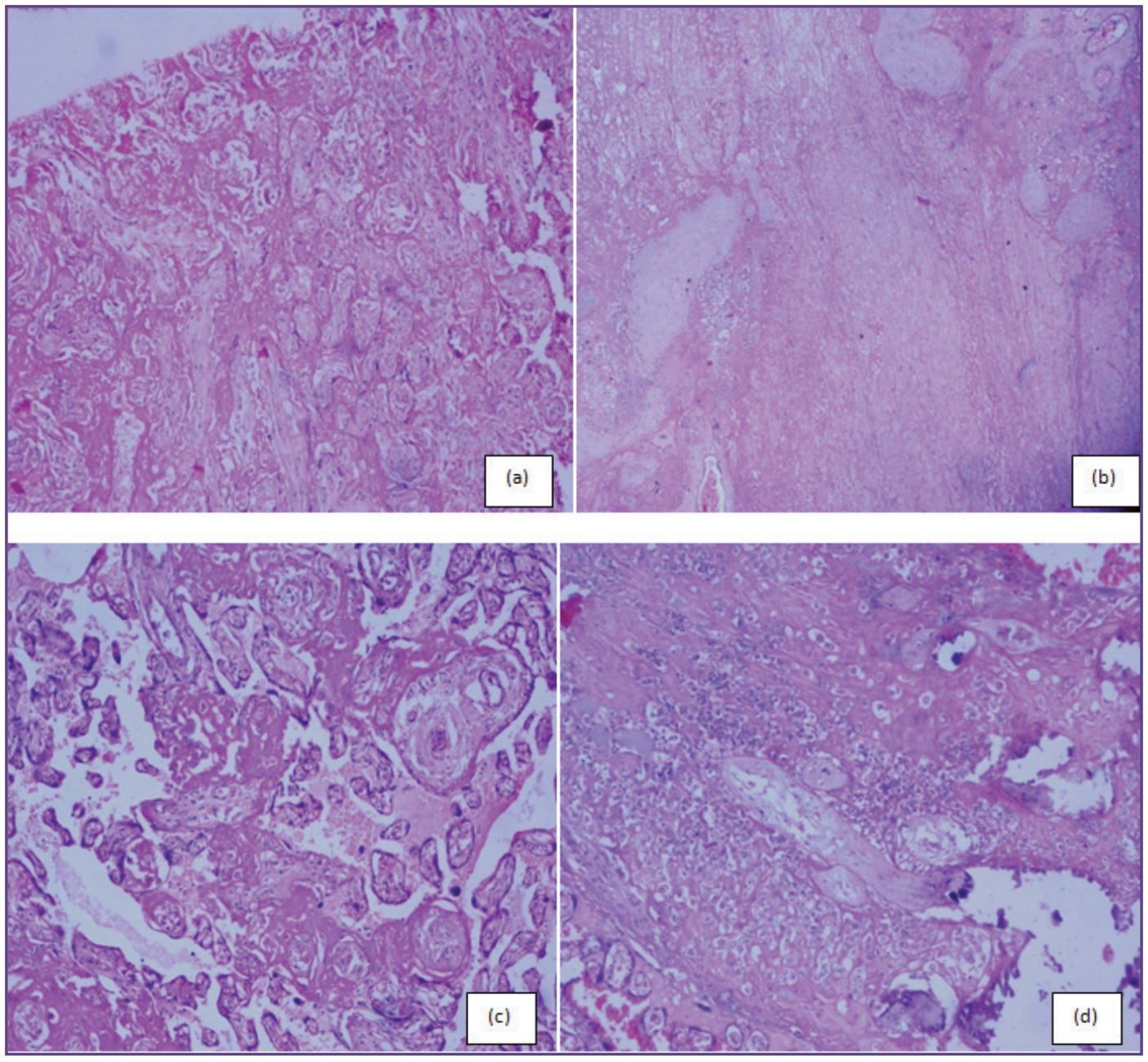

Fig. 1: Microphotographs (a) Old infarct showing crowding of ghost like villi (H\&E, x 100) (b) Intervillous thrombus showing linear streaks of fibrin and degenerated red blood cells (H\&E, x100) (c) Perivillous fibrin deposition (H\&E, x100) (d) Calcification (H\&E, x100). 

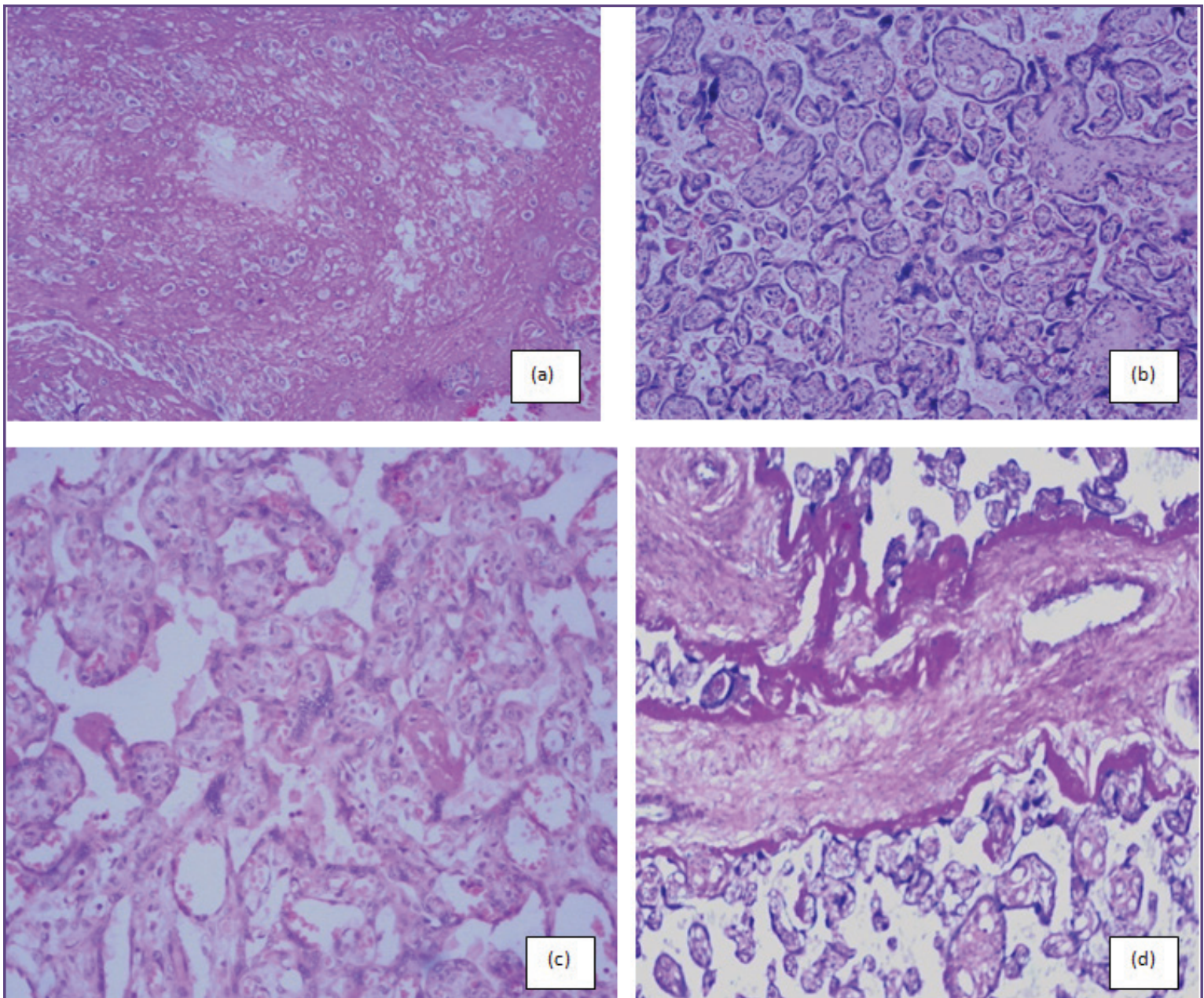

Fig. 2: Microphotographs showing (a) Cytotrophoblastic proliferation (H\&E, x100) (b) Increased syncytial knots (H\&E, x100); (c) Vasculosyncytial membrane in control group (H\&E, x200); (d) Thickened trophoblastic basement membrane (PAS, $\mathbf{x 1 0 0 ) .}$
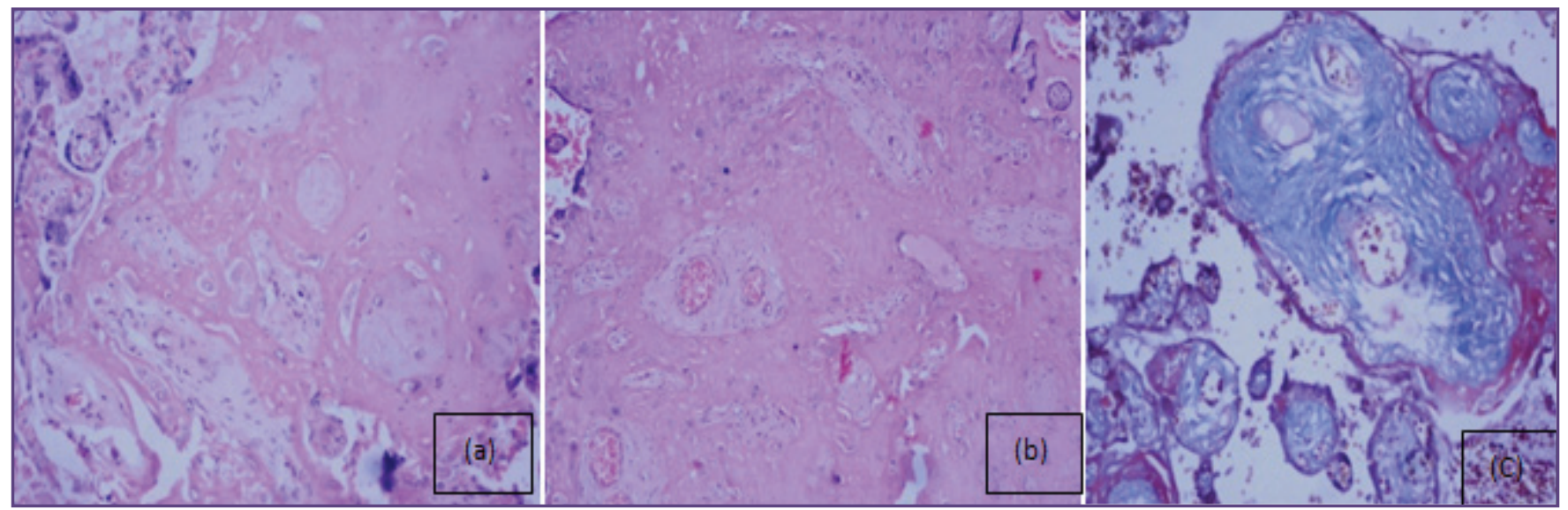

Fig. 3: Microphotographs showing (a) Fibrinoid necrosis (H\&E, x200); (b) Villous stromal fibrosis (H\&E, x40); (c) Villous stromal fibrosis (Masson's trichrome, x200). 


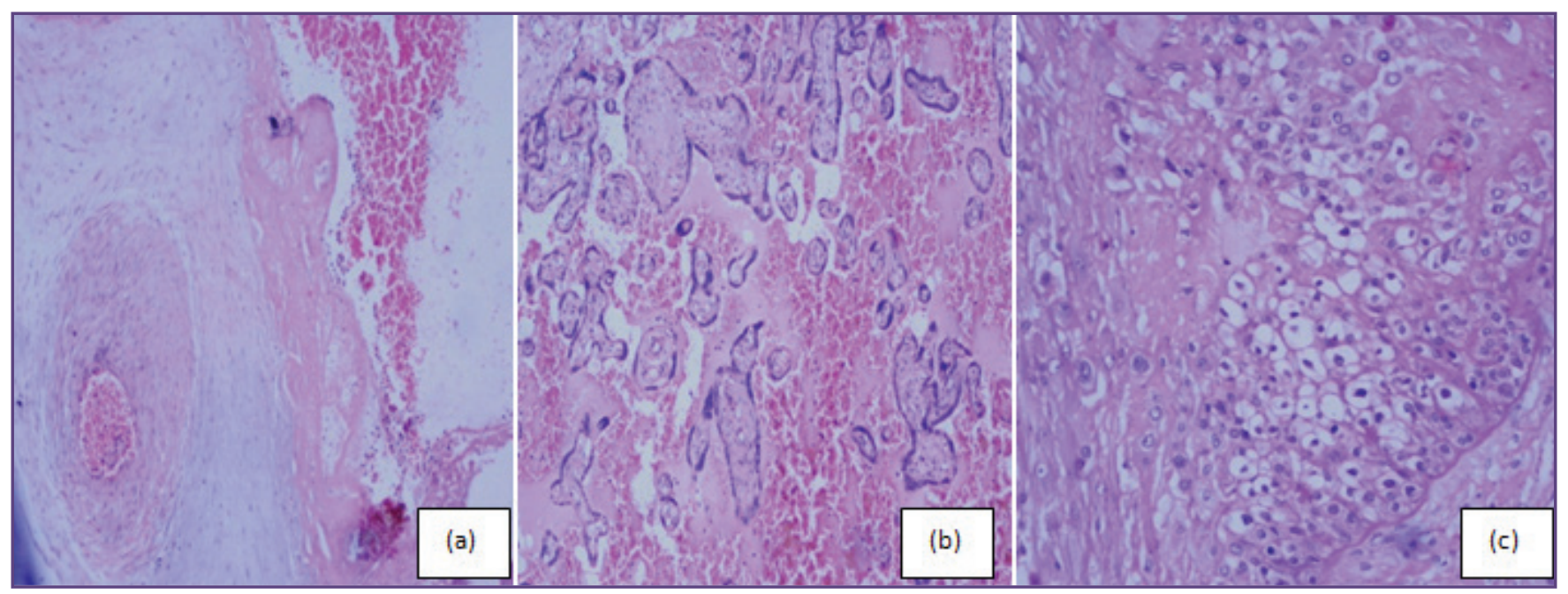

Fig. 4: Microphotographs showing, (a) Obliterative endarteritis (H\&E, x100); (b) Intervillous haemorrhage (H\&E, x100); (c) X cells of Wilkin (H\&E, x200).

\section{Discussion}

The placenta is a highly specialised organ of pregnancy described as an effective index for maternal and fetal status in pregnancy. The present study was undertaken to analyse the various deleterious effects of hypertension on the placenta in terms of gross, macroscopic and microscopic villous lesions which serve as a guide to the duration and severity of the disease.

The average placental weight and diameter was less in study group. The average weight of hypertensive placenta was $409 \mathrm{~g}$, the least weight recorded being $200 \mathrm{~g}$. Mallik et $\mathrm{al}^{\left[{ }^{77}\right]}$ reported five cases of hypertension with the placental weight less than $300 \mathrm{~g}$ and mean diameter of placenta to be $17.54 \mathrm{~cm}$. Ciblis ${ }^{[8]}$ reported that placenta from PIH cases were smaller than normal indicating an underlying pathological process interfering with the normal growth of placenta.

Placental infarction represents an area of ishaemic villous necrosis secondary to local obstruction of the maternal uteroplacental circulation. Minor degree of infarction is seen in about $25 \%$ of placentae from uncomplicated pregnancies and can therefore be regarded as an inconsequential phenomenon. ${ }^{[9]}$ Infarction involving more than $5 \%$ of placental parenchyma is clinically significant. ${ }^{[10]}$ In our study, significant infarction $(>5 \%$ surface area involved) was seen in $40 \%$ of hypertensive cases. Similar findings were noted by Bandana Das et $\mathrm{a}^{[11]}$, Udainia et $a^{\left[{ }^{[12]}\right.}$ and Narsimha et al. ${ }^{[13]}$

Calcification is regarded as evidence of placental ageing or maturation. ${ }^{[14]}$ The incidence of calcification in normal placenta in the present study was $60 \%$. In PIH cases, the overall incidence was $66 \%$ as observed in study by Pushpa et al. ${ }^{[15]}$ Retroplacental hematoma is significant if more than a third of the placental parenchyma is separated by the hematoma from the maternal uteroplacental vessels. It was seen only in one case as observed in study done by Kurudkar et al. ${ }^{[16]}$ Single Cysts were noted in one case of placentae from study group as compared to the study of Nobis and Das ${ }^{[17]}$ who found multiple chorionic cysts in two cases of toxaemic patients. Significant villous lesions were observed in the present study in hypertensive cases. These were attributed to the decreased maternal uteroplacental blood flow in hypertension due to maternal vasospasm as proposed by Brown and Veall. ${ }^{[18]}$

The incidence of villous hypovascularity was increased in hypertensive cases $(60 \%)$ comparable to Syed et al ${ }^{[19]}$ and Kalra et al. ${ }^{[20]}$ Significant villous cytotrophoblastic cell proliferation $(>20 \%)$ was observed in $83.34 \%$ of hypertensive cases. An increase in proliferation of villous cytotrophoblastic cells as a reaction to toxemia of pregnancy was reported by Kurudkar et a ${ }^{[16]}$, Kalra et al ${ }^{[20]}$ and Maqueo et al. ${ }^{[2]]} \mathrm{A}$ significant increase in syncytial knot formation in placental villi is a reflection of placental maturity or may be increased in hypoxia due to placental insufficiency. ${ }^{[22,23]}$ The syncytial knots were found to be higher in study group. Similar findings were described by Kalra et al ${ }^{[20]}$, Maqueo et a ${ }^{[21]}$ and Masodkar et al..$^{[24]}$

Paucity of the vasculosyncytial membrane is an index of fetal hypoxia. Vasculosyncytial membrane deficiency was significant in the study group comparable to finding by Fox $^{[25]}$ who reported a low vasculosyntitial membrane count (4.5-5.3\%) in hypertensive placentae and considered it to be a manifestation of villous regression. Fox ${ }^{[26]}$ considered that the reason for higher percentage of 
villi with thickened basement membrane is due to the proliferation of cytotrophoblastic cells, which secrete the basement membrane as a response to placental ischaemia. Villous basement membrane thickening with high basement membrane counts ( $>3 \%$ villi) was seen in $66.67 \%$ (20/30) cases of hypertensive pregnancies. These findings concurred with theories of other authors. ${ }^{[10,24,27]}$

Burstein et $\mathrm{al}^{[28]}$ have found that fibrinoid necrosis is a form of senile amyloid due to immune attachment on trophoblastic cells, which because of ageing process contains misspecified proteins. Significant fibrinoid necrosis was noted in $53.33 \%$ of hypertensive cases in accordance to other authors.

In the study group, there was a higher percentage of stromal fibrosis $(63.33 \%)$. The two factors responsible for the formation of stromal fibrosis are a normal aging process and a reduced uteroplacental blood flow. ${ }^{[19]}$ Endarteritis Obliterans is seen in hypertensive placentae. In the present study, endarteritis obliterans was observed only in study group (60\%). Similar findings were observed by Kalra et al. ${ }^{[20]} \mathrm{X}$-cells of Wilkin were seen in $33.33 \%$ of toxemic cases in the present study. A similar finding was reported by Fox. If the syncytiotrophoblast suffers ischemic damage, the cytotrophoblast proliferates in an attempt to replace the damaged tissue. The degree of cytotrophoblastic hyperplasia is related to the extent of syncytial damage and thus serves as a rough quantitative index of the severity of ischemia. ${ }^{[7]}$

\section{Conclusion}

Patients with PIH have increased chances of ishaemic damage to placental tissue along with maldevelopment of terminal villi. The reduction in placental weight and diameter was statistically significant in hypertensive cases. The incidence of placental infarct and intervillous thrombus was also higher in hypertensive cases.

The villous lesions in hypertensive placentae like villous hypovascularity, cytotrophoblastic proliferation, paucity of vasculosyntial membrane, thickening of basement membrane,stromal fibrosis and intervillous haemorrhage were found to be statistically significant in study group. So, a careful examination of placenta after delivery can provide a valuable insight into the mechanism of placental dysfunction in detail.

\section{References}

1. Benirshkek. Pathology of the human placenta 2nd ed. New York: Springer Verlog;1990.

2. Jain K, Kavi V, Raghuveer C et al . Placental Pathology in PIH with or without IUGR. Indian J. Pathol. Microbiol.2007; $50(3)$ : 533-537.
3. Emin M, Anna I. Bakardjiev, Susan J. The placenta : transcriptional, epigenetic, and physiological integration during development. J Clin Invest. 2010; 120(4) : 1016-25.

4. Udainia A, Jain ML. Morphological study of placenta in pregnancy induced hypertension with its clinical relevance, J Anat Soc. India. 2001; 50(1): 24-27.

5. Fernando Arias. In: Mosby. Practical guide to high-risk pregnancy and delivery. 2nd Edition. Harcourt Asia Private Ltd; 2000:184-185.

6. Cunningham F, Leveno K, Bloom S, Hanth J, Rouse D, Spong C. Pregnancy hypertension. In: Williams Obstetrics. 23rd ed. New York : McGraw Hill ; 2009. 706-756.

7. Mallik GB, Mirchandani JJ, Chitra S. Placenta in intrauterine growth retardation. J Obstet Gynaecol India .1979; 29: 805-10.

8. Cibilis LA. The placenta and newborn infant with hypertension conditions. Am J Obstet Gynaecol. 1974; 118:256-70.

9. Juan Rosai. Surgical Pathology.10th ed. New York. Elsevier. 2011.1649.

10. Kher AV, Zawar MP. Study of placental pathology in toxemia of pregnancy and its fetal implications. Indian J Pathol Microbiol. 1981; 24:245-51.

11. Bandana Das, Dutta D, Chakraborthy S, Nath P. Placental morphology in hypertensive disorders of pregnancy and its correlation with fetal outcome. J Obstet and Gynecol India. 1996; 46(1) :40-46.

12. Udainia A, Bhagwat SS, Mehta CD. Relation between placental surface area, infarction and foetal distress in pregnancy induced hypertension with its clinical relevance. J Anat Soc Ind. 2004; $53:$ 27-30.

13. Narsimha A, Vasudeva DS. Spectrum of changes in placenta in toxaemia of pregnancy. IAPM. 2011; 54:15-20.

14. Fox H. General pathology of the placenta. In: Fox H, editor. Haines and Taylor Obstetrical and Gynecological Pathology. 4th ed. Edinburgh: Churchill Livingstone; 1995. 1480-2.

15. Goswami P, Lata H, Memon S, Khaskheli LB. Excessive Placental Calcification Observed in PIH Patients and its Relation to Fetal Outcome. JLUMHS. 2012;11(03):143-148.

16. Kurdukar MD, Deshpande NM, Shete SS, Zawar MP. Placenta in PIH. Indian J Pathol Microbiol. 2007 ; 50 (3):493-7.

17. Nobis P, Das U. Placental morphology in hypertensive pregnancy. J Obstet Gynecol .1990 ; 40:166-9.

18. Browne JC, Veall N. The maternal blood flow in normotensive and hypertensive women. J Obstet Gynaecol Br Emp. 1953 ; 60:141-7.

19. Sayeed M, Chakrawarti RN, Devi PK. A comparative study of placental villous changes in normal and abnormal pregnancies. J Obstet Gynaecol India .1976; 26 : 217-21.20.

20. Kalra VB, Aggarwal A, Sareen PM. Histopathological changes in placenta in toxemia of pregnancy. J Obstet Gynaecol India. 1985; 35: 86. 
21. Maqueo M, Azuela JC, Manuel Dosal de la Vega. Placental pathology in eclampsia and pre-eclampsia. Obstet Gynaecol. 1964; 24: 350 .

22. Kristina L, Raanan S, Rebecca B. Synctial knots as a Reflection of Placental Maturity : Reference values for 20 to 40 weeks gestational age.In: Pediatric and Developmental Pathology.2009; 28: 28-37.

23. AEP, Moll SJ, Jones CJ, Baker PN, Crocker IP. Formation of syncytial knots is increased by hyperoxia, hypoxia and reactive oxygen species. Placenta 28 2007(Suppl A):33-40.

24. Masodkar AR, Kalamkar LR, Patke PS. Histopathology of placenta and its correlation with fetal outcome. J Obstet Gynaecol India. 1985; 35:294-7.
25. Fox $\mathrm{H}$. The incidence and significance of vasculosyncytial membranes in the human placenta. J Obstet. Gynaec Brit.C rquote Wealth. 1967; 74:28.

26. Fox $\mathrm{H}$, Basement membrane changes in the villi of human placenta. J Obstet Gynaecol Brit C\rquote Wealth. $1968 ; 75: 302$.

27. Sodhi S, Mohan H, Jaiswal TS, Mohan PS, Rathee S. Placental pathology in pre eclampsia- eclampsia syndrome. Indian J Pathol Microbiol. 1990;33:11-6.

28. Burstein R, Frankel S, Soule S.D et al. Ageing of the placenta: Autoimmune theory of senescence. Am J Obstet Gynaecol.1973; 116:271.

*Corresponding author:

Dr. Vandana Porwal, 450/29, Opposite Old Temple, Mayo Link Road, Ajmer (Raj.) INDIA

Phone: +91 9460355266

Email: Vandana2067@gmail.com

Date of Submission : $\mathbf{1 5 . 1 0 . 2 0 1 6}$

Date of Acceptance : 07.12.2016

Financial or other Competing Interests: None.
Date of Publication : 19.02.2017 